\title{
Ver, ler e escrever: a imprensa e a construção da imagem no cinema brasileiro na década de 1950
}

Seeing, reading and writing: the press and the construction of images, the Brazilian cinema during the Fifties

Meize Regina de Lucena Lucas*

RESUMO

O Artigo analisa a importância da imprensa na década de 1950 na construção de uma cultura cinematográfica do país em novas bases. Estudar esse momento é fundamental para compreender a estética cinematográfica da década seguinte bem como o campo de produção, circulação e recepção dos filmes. São analisados os suplementos culturais dos jornais O Estado de S. Paulo e Jornal do Brasil e a Revista de Cinema. Três questões se destacam: a relação espectador/leitor, o lugar da crítica e o papel das cinematecas na formação de uma cultura letrada.

Palavras-chave: suplementos; cultura cinematográfica; crítica.

\section{ABSTRACT}

This article analyses the importance of press in the 1950's for the construction of a Brazilian new-based cinematographic culture. Studying this period is crucial to the understanding of the cinematographic aesthetics of the following decade, as well as the film production, circulation and reception fields. The object of the analysis are the cultural supplements of two newspaper - $O$ Estado de S. Paulo and Jornal do Brasiland a magazine - Revista de Cinema. Three aspects will be highlighted: the viewer/reader relationship, the place of criticism and the role of film libraries in the making of a literature culture.

Keywords: supplements; cinematographic culture; criticism.

No Brasil da década de 1960, a paixão pelo cinema levava aos prazeres da leitura e da escrita. Para muitos essas três atividades eram indissociáveis, pois a leitura e a escrita permitiam uma outra forma de fruição dos filmes.

Essa mudança no forma de ver e experimentar os filmes relaciona-se diretamente à formação de uma nova cultura cinematográfica impulsionada

\footnotetext{
* Professora Titular do Depto. de História - Universidade Federal do Ceará (UFC), Av. da Universidade - Benfica.60000-000 Fortaleza - CE - Brasil. meizelucas@gmail.com.
} 
por importantes transformações no campo editorial brasileiro, principalmente, a imprensa. Os anos 50 foram marcados pela publicação dos primeiros livros sobre cinema brasileiro, pelo aparecimento dos suplementos literários nos grandes jornais, caso do Jornal do Brasil e de O Estado de S. Paulo, e pela consolidação de uma revista especializada em cinema de cunho teórico e ensaístico, a Revista de Cinema, de Belo Horizonte.

As cinematecas do Rio de Janeiro e de São Paulo, criadas nessa mesma década, constituíram espaço de reunião e debate para jovens cinéfilos, permitiram a formação de uma geração de espectadores através de suas exibições, retrospectivas e mostras e também tiveram importante papel na produção e circulação de uma literatura sobre cinema.

A dificuldade de acesso à Revista de Cinema, pelo fato de ser publicada em Belo Horizonte, e a jornais de outros estados, principalmente do Rio de Janeiro e de São Paulo, era suprida, em parte, pelos boletins produzidos pelos cineclubes, pelos grupos de estudo e pelas cinematecas que promoviam a troca de material e informação entre diferentes entidades. Também foram muitos os jovens que deram início à organização de pequenos arquivos particulares. Nos cineclubes de orientação católica, o acesso a obras estrangeiras dava-se por meio dos padres, que podiam importar livros mais facilmente. As cinematecas, ao organizarem bibliotecas e arquivos de fontes impressas, constituíram um valioso acervo para o qual afluíam pesquisadores e cinéfilos. Seus funcionários, em grande parte jovens aficcionados por cinema, tinham acesso a esse material, caso de Maurice Capovilla, Jean-Claude Bernardet e Gustavo Dahl, em São Paulo, e Walter Lima Júnior, no Rio de Janeiro. Todos igualmente se dedicavam à escrita sobre os filmes e traçariam, posteriormente, importante carreira no cinema.

A escrita e o trabalho na cinemateca constituíram algumas das primeiras formas de aproximação profissional do campo cinematográfico. As trajetórias dos jovens que passaram à realização pouco tempo depois, final da década de 1950 ou início da década de 1960, convergem em razão da semelhança: eram membros de cineclubes, críticos de jornais, funcionários da cinemateca. É o caso dos já referidos Gustavo Dahl, Maurice Capovilla e Walter Lima Jr., e também de Leon Hirszman, Cacá Diegues e Glauber Rocha, para citar alguns exemplos de pessoas que se dedicaram ao cinema e que mais tarde fizeram cinema. Dedicar-se ao cinema significava ver, ler, escrever, discutir cinema e, especialmente, fazer da divulgação do cinema e de parâmetros de apreciação crítica uma prática.

O prazer do espectador andava a par do prazer do leitor. A leitura per- 
mitia não só um aprofundamento da apreciação do filme, mas também o acompanhamento dos debates sobre a situação do cinema brasileiro. Assim, entender o texto em sua multiplicidade significa criar chaves de compreensão para estudar a cultura visual em gestação naqueles anos.

Essa época que antecede à realização pode ser considerada um período vivido como um aprendizado do olhar. A crítica feita ao cinema então produzido era acompanhada de propostas para um cinema a ser feito. Um cinema do desejo, do futuro. Portanto, quando posteriormente são criados mecanismos econômicos e estruturais que permitiram a realização desse cinema o público para ele já estava formado, pelo menos pela palavra. Quando os primeiros filmes do chamado Cinema Novo começaram a ser feitos, o texto continuou desempenhando função essencial na atividade cinematográfica e na fruição fílmica.

O público desses circuitos de exibição possuía um campo comum de referências com os realizadores, pois havia uma experiência anteriormente compartilhada, assim como os códigos de compreensão fílmica. Ao mesmo tempo em que o público das cinematecas, cineclubes e festivais voltava-se para o passado, formando uma rica cultura cinematográfica, estava igualmente aberto ao futuro na medida em que buscava e partilhava novas formulações estéticas.

\section{JORNAL: ENTRE MUDANÇAS E INCERTEZAS}

O Suplemento Dominical do Jornal do Brasil, segundo Alzira Alves de Abreu, ao lado dos suplementos dos jornais Correio da Manhã, O Estado de S. Paulo e Diário Carioca, seria aquele que abria espaço predominantemente para os movimentos de vanguarda, seja na literatura, nas artes plásticas, no cinema ou no teatro. ${ }^{1}$ A década de 1950 foi um momento de reformulação de vários jornais, entre os quais se incluiu o $J B$, levada adiante por Odilo Costa Filho. Este empreendeu a organização de uma nova equipe composta por jornalistas jovens, egressos do Diário Carioca e da Tribuna Carioca, entre os quais Jânio de Freitas, Carlos Castelo Branco, Carlos Lemos, Wilson Figueiredo, Amilcar de Castro, Ferreira Gullar e José Carlos de Oliveira. A criação do Suplemento Dominical coube a Reinaldo Jardim.

Em junho de 1956, o Jornal do Brasil iniciou a publicação do Suplemento Dominical, abrindo suas páginas para longos ensaios sobre literatura, filosofia, música, balé e artes plásticas, escritos por intelectuais como a crítica 
teatral Bárbara Heliodora, o poeta Ferreira Gullar e o filósofo Benedito Nunes. Ao lado dos ensaios, pequenas notas davam notícia dos acontecimentos das vidas culturais carioca, nacional e estrangeira. Esse foi o espaço ocupado pelo cinema durante vários meses: notas sobre os lançamentos de filmes, informes sobre os festivais de cinema, comentários dos bastidores de filmagens.

Nas páginas diárias repetiam-se notícias do mesmo gênero nas colunas de cinema, que dividiam espaço com fotos e fofocas sobre astros e estrelas. Os comentários sobre filmes, ou seja, os lançamentos da semana discorriam sobre o enredo e teciam breves considerações sobre a direção, a fotografia, a música e o trabalho dos atores.

Quando os ensaios sobre cinema finalmente passaram a ocupar as páginas do Suplemento Dominical, caracterizaram-se por sua irregularidade, rotatividade dos críticos e reduzido número de caracteres - cerca de meia página - se comparado às demais colunas.

$\mathrm{O}$ mesmo $J B$ se orgulharia anos depois de estampar em página inteira com letras em caixa alta que "foi o primeiro da imprensa brasileira a publicar uma coluna dedicada exclusivamente ao cinema", ${ }^{2}$ por ocasião da indicação do filme A hora e a vez de Augusto Matraga, de Roberto Santos, como representante brasileiro para o Festival de Cannes de 1966. Nesse ínterim, e nos anos que se seguiram, surgiram em suas páginas artigos de Gláuber Rocha e de reconhecidos críticos de cinema como Ely Azeredo, José Carlos Avellar e José Lino Grünewald, além de traduções de estudos de importantes teóricos de cinema, como Eisenstein, Béla Balázs e Pudovkin. Algo, portanto, aconteceu durante essa década.

Inaugurada 'oficialmente' em 10 de fevereiro de 1957, a coluna de cinema chegava ao suplemento com mais de seis meses de atraso. $\mathrm{O}$ primeiro artigo, uma reflexão sobre a crítica de cinema, foi assinado por José Carlos de Oliveira e José Lino Grünewald. Este se tornou destacado crítico de cinema, mas especialmente nas páginas do Correio da Manhã, e José Carlos ganhou no jornal uma coluna fixa, que atravessou décadas, e notabilizou-se na imprensa, mas como cronista. Outros nomes passaram pela coluna, como Miguel Borges, Cláudio Bueno e Glauber Rocha. Entre fevereiro e março de 1958 a seção de cinema foi suspensa; retornou em abril, e, segundo o jornal, passaria a ser semanal e escrita pelo crítico Ely Azeredo. No entanto, a irregularidade da coluna permaneceu, assim como a rotatividade dos jornalistas responsáveis pela coluna. Somente anos depois Ely Azeredo tornar-se-ia crítico 'oficial' do $J B$, escrevendo quase que diariamente sobre cinema no Caderno B.

Nessa coluna 'inaugural' do Suplemento Dominical de 10 de fevereiro de 
1957, José Carlos Oliveira e José Lino Grünewald discutem sobre o que é fazer crítica de cinema. Segundo os dois jornalistas, o crítico é alguém que diante da tela pratica uma ação, pois conta com instrumentos para analisar o filme e extrair sua significação, enquanto o espectador, destituído desses instrumentos, adota uma atitude passiva. Esse não teria passado de um primeiro estágio da cultura cinematográfica que se limita à mera compreensão da linguagem cinematográfica. $\mathrm{O}$ espectador, se comparado ainda ao leitor, está novamente em desvantagem, pois a tradição crítica literária encontra-se tão enraizada e disseminada que é impossível ao leitor não realizar, mesmo que inconscientemente, a ação crítica-analítica ao ler um texto. E os bancos escolares se encarregaram do exercício cotidiano de análise textual. Ao espectador não é dado nenhum instrumental de análise. Daí, por essa dupla inconsistência do espectador de cinema, afirmarem a necessidade do 'caráter didático' de seus escritos.

A imagem e o espectador estavam, portanto, distantes do lugar seguro que o texto representava. No Brasil, a literatura, inclusive a nacional, já havia garantido seu lugar de produção e consumo. A crítica literária era componente ativa do campo editorial no Brasil e havia muito estava presente nos jornais de circulação nacional. A publicação de um conto ou a avaliação positiva de uma obra pelos críticos de reconhecidos jornais podia garantir o surgimento de um novo talento literário no país ou o aumento nas vendas de alguns títulos.

O jornal, especialmente nas grandes capitais, passou também a funcionar a partir de meados dos anos 50 como um locus privilegiado de interlocução das pessoas ligadas ao cinema e um espaço em que se constituía uma cultura cinematográfica em novos termos. Ele ampliou a comunidade de leitores especializada na cultura cinematográfica, tornou-se veículo de expressão dos realizadores (diretores, produtores, técnicos), disseminou uma nova percepção do que seria o cinema, permitiu o acesso a uma literatura disponível somente em língua estrangeira através da tradução de textos de teóricos e estudiosos de renome internacional e, por fim, abriu espaço para matérias que tratavam dos problemas da realização e da circulação da produção nacional.

\section{CINEMA BRASILEIRO: UMA HISTÓRIA NECESSÁRIA}

Ainda em 1956, a partir de 6 de outubro, O Estado de S. Paulo passou a publicar aos sábados o Suplemento Literário. Este abrangia seis páginas com 
o mesmo tamanho dos demais cadernos, ou seja, no formato standard padrão (aproximadamente $56 \mathrm{~cm}$ de largura e $76 \mathrm{~cm}$ de altura), e contava com seções fixas sob a responsabilidade de um corpo de redatores e colaboradores permanentes, tendo, entre estes últimos, nomes como os de Carlos Drummond de Andrade, Fernando Sabino, Gustavo Corção, Ledo Ivo, Otto Lara Resende, Paulo Mendes Campos, Sérgio Buarque de Holanda e Sérgio Milliet. Suas seções dividiam-se em literárias e artísticas, e o segundo grupo compreendia as artes plásticas, a música, o teatro e o cinema, sob a responsabilidade de Lourival Gomes Machado, Alberto Soares de Almeida, Sabato Magaldi e Paulo Emilio Salles Gomes, respectivamente. Além das seções fixas, havia as "seções livres" ocupadas por artigos, cujos temas e abordagem eram deixados à iniciativa do colaborador, e por contos e poemas.

Desde o início dos anos 50, o jornal publicava artigos, crônicas e crítica literária sem espaço e dia determinados, contando com a colaboração de diferentes escritores e intelectuais, muitos oriundos da Universidade de São Paulo. Em poucos anos surgiu um espaço específico para essa produção, a seção dominical "Literatura e Arte", no terceiro caderno, publicada a partir de dezembro de 1952.

No domingo 9 de setembro de 1956, na página 12 do primeiro caderno, o jornal anunciou o início da publicação de seu suplemento, apresentando sua concepção, organização, redatores e colaboradores. O sociólogo e crítico Antonio Candido, a convite de Júlio de Mesquita Neto (cuja família é proprietária do jornal desde 1885), foi o responsável pelo projeto do suplemento. Optando por chamar nomes de vanguarda, Candido coloca a cultura universitária em primeiro plano, fazendo esse o elemento de distinção do suplemento paulista em relação aos demais. A remuneração dos colaboradores, acima da média praticada pelos outros jornais, foi destacada no anúncio do dia 9: "Pode-se afirmar que a publicação desempenhará certamente papel importante em nosso meio, inaugurando uma fase de remuneração condigna do trabalho intelectual e obedecendo a um planejamento racional, que exprime seu programa". ${ }^{3}$ A valorização da intelectualidade integrante do suplemento é destacada ao elencar seus nomes e ao referir-se à questão da remuneração condizente. Esta última, aliás, foi uma exigência de Antonio Candido à família Mesquita, da qual obteve aceite assim como para todo o seu projeto. Após sua colocação em marcha, coube ao jornalista Décio de Almeida Prado dirigir o suplemento, função em que permaneceu por vários anos.

Na página 5 do suplemento, teatro e cinema dividiam espaço. Raras foram as ocasiões em que a coluna de cinema esteve ausente ou foi deslocada 
em função de algum ensaio especial e mais longo que demandasse maior número de colunas. Diferentemente da crítica diária, muitas vezes anônima, ${ }^{4}$ os textos, quase todos de caráter ensaístico, eram assinados e escritos regularmente pela mesma pessoa.

Ao longo de uma década, Paulo Emílio Salles Gomes escreveu mais de duas centenas de artigos no Suplemento Literário, principalmente entre os anos de 1956 e 1962. As reformas editoriais e gráficas empreendidas no suplemento a partir de 1962 alteraram o perfil do caderno, e a coluna de cinema, assim como outras, deixou de ser fixa, passando a haver maior rotatividade dos colaboradores.

Apesar de responsável pela maior parte dos artigos publicados nesses primeiros anos, Paulo Emílio dividiu a coluna com críticos de outras publicações, colegas de jornal e da Cinemateca Brasileira, ${ }^{5}$ caso de Cyro Siqueira, jornalista mineiro e um dos criadores da Revista de Cinema; Rudá de Andrade, pesquisador, diretor, membro da Cinemateca Brasileira e futuro professor da Escola da Comunicação e Artes da Universidade de São Paulo; Francisco Luiz de Almeida Salles, crítico do jornal desde 1950 e primeiro presidente da Cinemateca Brasileira; Gustavo Dahl, membro da Cinemateca Brasileira e futuro diretor após estudar cinema no Centro Sperimentale di Cinematografia de Roma; Jean-Claude Bernardet, jornalista, membro da Cinemateca Brasileira e futuro roteirista e professor de cinema; e Maurice Capovilla, membro da Cinemateca, jornalista e futuro diretor de cinema.

A Cinemateca estava presente no suplemento não apenas pela constância de seus membros nas páginas do jornal, a começar por Paulo Emílio, conservador da instituição. Foram inúmeros os artigos por ele dedicados à importância da preservação de filmes para a formação cultural do país, e outros tantos focalizaram o trabalho da Cinemateca Brasileira. Paulo Emílio era ainda vice-presidente da FIAF (Fédération Internationale des Archives du Film) e membro de seu Comitê Diretor.

Os primeiros artigos publicados no suplemento intitulavam-se "Um pioneiro esquecido" e "O Congresso de Dubrovnik", ambos de Paulo Emílio e publicados em 6 e 13 de outubro de 1956, respectivamente. O título do primeiro seria uma referência a um projeto da Cinemateca, uma homenagem aos pioneiros da cinematografia no Brasil, em especial o cineasta e exibidor paranaense Anibal Requião; e o segundo expunha as principais resoluções e discussões do XII Congresso da Federação Internacional dos Arquivos do Filme, no qual se destacava a atuação das cinematecas que, a partir do trabalho de preservação dos filmes, permitiam a difusão da cultura cinematográfica. 
No primeiro artigo, Paulo Emílio traça um pequeno histórico dos primeiros realizadores do país e de sua produção, informa sobre o estado de conservação dos filmes (quando eles ainda existem) e trata de situar sua importância dentro do contexto cinematográfico nacional. O gancho inicial do texto, reiterado ao final, é o projeto da Cinemateca de homenagear esses realizadores por meio da projeção de seus filmes. Mas a essa realização precede a localização e a conservação dos filmes. A ação da Cinemateca, que aparece de forma periférica, constituirá a questão central do artigo seguinte. Afirma que o ponto de partida para a construção de uma cultura cinematográfica é a preservação de filmes:

Foram extremamente numerosas a partir de mais ou menos 1920 as tentativas do movimento de cultura cinematográfica em diferentes países. A razão pela qual essas iniciativas foram condenadas ao fracasso parece-nos hoje simples e clara: não há cultura sem perspectiva histórica, e como conhecer a história do cinema se os filmes não forem conservados?

A condição de existência do cinema é, portanto, sua inserção numa perspectiva histórica. História, preservação e produção formam um todo orgânico em seu pensamento. É impossível produzir no país se não pudermos retornar ao passado: "A volta ao filme é tão importante para a cultura cinematográfica quanto a volta ao texto para a literatura, porém muito mais problemática". ${ }^{7}$ Problemática, pois a conservação de filmes é muito mais cara e não é considerada essencial à cultura do país. A literatura, inclusive a nacional, já garantira seu lugar na cultura brasileira, enquanto acerca do cinema ainda se perguntava sobre seus sucessivos fracassos no país. A crítica literária já avaliara nossa produção, enquanto a cinematográfica ainda estava por fazer a sua. Somente a salvaguarda dos filmes permitiria a escrita de uma história do cinema; jornais e memórias utilizados até então eram instrumentos necessários, mas insuficientes, para levar a cabo tal tarefa.

Problemática ainda, pois a conservação de filmes não pode prescindir de uma ação governamental, em razão de seus altos custos, num país que sequer conseguira consolidar uma indústria cinematográfica e em que produtores e realizadores pouco retorno tiveram aos seus apelos que, junto às instâncias federais, reivindicavam uma política protecionista ao cinema brasileiro.

Defender a preservação de filmes era igualmente defender a manutenção da Fundação Cinemateca Brasileira, cujos projetos, problemas e ações ocupavam continuamente artigos do suplemento. Para os livros, a Biblioteca 
Nacional; para os filmes, a Cinemateca Brasileira. ${ }^{8}$ Ao lado da defesa da Cinemateca Brasileira, a constante divulgação da Cinemateca do MAM do Rio de Janeiro, criada pelo crítico Moniz Viana e por Ruy Pereira da Silva. ${ }^{9}$ As duas instituições em diversas ocasiões trabalharam conjuntamente.

Entre 1958 e 1962, Moniz Viana organizou reputados festivais de história do cinema no MAM: americano (com a colaboração da Cinemateca do Museu de Arte Moderna de Nova York, 1958), francês (com a colaboração da Cinématèque Française e do Ministério da Cultura da França, 1959), italiano (com a colaboração da Cineteca Nazionale, de Roma, da Cineteca Italiana, de Milão, e do Museo Nazionale del Cinema, de Turim, 1960), russo e soviético (com a colaboração da Cinemateca Brasileira, 1961) e britânico (com a colaboração do British Film Institute, 1962). A cada festival seguiu-se o lançamento de um catálogo, reunindo alguns dos principais críticos do país e, por vezes, dando oportunidade aos jovens apreciadores da arte cinematográfica.

Os festivais russo, soviético, italiano, francês e americano também foram exibidos em São Paulo. Conjuntamente às imagens, os catálogos constituíam importantes instrumentos de reflexão acerca da produção cinematográfica. Em muitos casos, eram a única bibliografia disponível em português referente a determinadas cinematografias.

Em poucos anos - menos de uma década - o público carioca e, especialmente, o paulista, tiveram a oportunidade de conhecer considerável parte da história do cinema mundial. Eram centenas de filmes registrados na história do cinema mundial e classificados pela crítica especializada como clássicos, vanguardistas, expoentes, marcos. As exibições, acompanhadas pelos catálogos e pelos artigos do jornal promoviam a valorização do cinema como elemento de culto artístico e formavam um público leitor. Em textos e imagens formou-se uma geração de espectadores, entre os quais muitos futuros cineastas, fotógrafos, roteiristas, produtores, críticos, pesquisadores, jornalistas. Enfim, aqueles que trabalhariam com cinema nas décadas seguintes e os que formariam seu público.

A consolidação da Cinemateca era considerada uma conquista nacional. Em São Paulo, segundo palavras de setores da imprensa, estariam os agentes e espaços formuladores da nova cultura cinematográfica brasileira. Os artigos do Suplemento Literário dotavam de positividade as ações que envolviam a Cinemateca e demais iniciativas que partiam da capital paulista. Situava-se na história do cinema nacional e, por vezes, do latino-americano a importância dos acontecimentos da vida cultural que ali transcorriam. ${ }^{10}$

A Cinemateca Brasileira era pólo de formulação de projetos para o cine- 
ma. Não o único mas, talvez, o de maior visibilidade, por conta dos inúmeros canais do qual se valia, entre eles a imprensa, a publicização do reconhecimento de entidades culturais nacionais e estrangeiras, os contatos com as esferas públicas de poder. A existência e a ação da entidade por longos anos, apesar dos inúmeros reveses financeiros, políticos e físicos — inclusive um incêndio que destruiu parte de seus arquivos em 1957 —, ajudavam na manutenção do espaço conquistado. A respeitabilidade e o reconhecimento que a instituição e seus membros detinham no meio cinematográfico garantiam sua projeção e ampliavam sua capacidade de atuação.

No momento em que fazia a defesa intransigente da Cinemateca pelas páginas do jornal, Paulo Emílio construía as bases de uma cultura cinematográfica em novos termos. Reintegrava o cinema nacional no cenário internacional não pela via da produção, e sim, pela da relação entre a sociedade e a cultura. Até então, buscara-se aproximar o produto nacional do estrangeiro através dos modelos de produção — apostando nos grandes estúdios, caso da Vera Cruz — e da linguagem — valorizando filmes que representassem o país segundo uma estética consagrada no exterior.

Paulo Emílio propunha avaliar nossa produção dentro de uma perspectiva histórica, social e cinematográfica brasileira. Para ele, conhecer a história do cinema internacional e ter familiaridade com essas produções era indispensável para a formação cinematográfica brasileira. Mas essa formação seria precária sem o conhecimento da produção nacional, buscando perceber seu significado no desenvolvimento de uma cinematografia local. A possibilidade de transformação e consolidação de um novo cinema só é possível mediante esse olhar que lança para o exterior e ao mesmo tempo se volta para sua própria tradição, buscando entendê-la em sua historicidade.

Ao reclamar junto aos poderes públicos sua atuação no incentivo à produção e, principalmente, sua responsabilidade na preservação, insere o cinema na cultura nacional ao transformá-lo em patrimônio. Repetidas vezes traçaram-se paralelos entre a Biblioteca Nacional, o Museu Nacional e a Cinemateca.

O cinema deveria deixar o círculo dos iniciados, dos profundos conhecedores das minúcias da história mundial do cinema, dos debatedores do 'específico fílmico', para se integrar à sociedade, ou seja, à cultura nacional:

A experiência de países como a França e a Itália, onde já existe uma tradição cineclubista, demonstra que freqüentemente pode ser desastroso o resultado dos esforços mais bem intencionados: há geralmente nos clubes de cinema certa fau- 
na constituída de verdadeiras aberrações intelectuais. Trata-se de pessoas que reduziram suas vidas ao interesse exclusivo pelo cinema. Por maior que seja a massa de noções e informações armazenadas por esse tipo de cineclubista, não caberia a seu propósito falar-se de cultura cinematográfica. Essa idéia é inseparável de cultura, simplesmente. A familiaridade com o fato cinematográfico só é real quando a formação especializada se articula com um fundo mais geral de outros interesses e conhecimentos, artísticos e humanísticos. ${ }^{11}$

Impossível pensar o cinema fora da cultura, da sociedade e da história. Paulo Emílio dedicou vários ensaios à discussão dessas questões e as utilizou incessantemente como referencial para abordar outros assuntos, fossem os festivais de cinema, a trajetória de importantes cineastas ou análises de filmes.

\section{O CINEMA BRASILEIRO ENTRE A CRÍTICA E OS CRÍTICOS}

Nos mesmos anos em que se desenvolve a atividade jornalística no Suplemento Literário, Alex Viany trabalha em sua obra Introdução ao Cinema Brasileiro. O livro, em sua edição original, ${ }^{12}$ compunha-se de uma história do cinema brasileiro e um apêndice com a filmografia de cerca de quinhentos títulos, em ordem alfabética, de fitas produzidas no Brasil desde 1906, acompanhadas de informações a respeito do local e data de realização, nome da produtora e dos principais técnicos e atores.

As referências anteriores à história do cinema brasileiro limitavam-se a poucos títulos, como o livro de F. Silva Nobre intitulado Pequena História do Cinema Brasileiro, de 1955, a publicação em revista de artigos seriados, caso da seção "Notas sobre o Cinema Brasileiro", de responsabilidade de José Roberto Duque Novaes, na Revista de Cinema, e "História do Cinema Brasileiro", de Adhemar Gonzaga, publicada pelo Jornal de Cinema,${ }^{13}$ entre outras espalhadas por jornais e revistas.

A preocupação com o conhecimento histórico de nossa produção era uma problemática que começava a ser compartilhada por parte da crítica ou, pelo menos, ganhava visibilidade naquele momento. No prefácio de seu livro, Alex Viany agradece a Adhemar Gonzaga, Pedro Lima, Jurandir Noronha e Pery Ribas, entre outros, pela valiosa ajudada prestada, ao abrirem seus arquivos para consulta e o auxiliarem com informações de suas vivências no mundo cinematográfico brasileiro.

Alex Viany, no seu ansiosamente aguardado livro Introdução ao Cinema 
Brasileiro, escreve a história da produção realizada no Brasil, especialmente os longa-metragens de ficção: é uma história basicamente de filmes e de realizadores. Dividido em três partes - período mudo e os ciclos de Recife e Campinas; surgimento do cinema falado; Vera Cruz e estúdios contemporâneos - , nas duas últimas dá início a algumas reflexões sobre os problemas do desenvolvimento do cinema no Brasil em termos econômicos e políticos. Recorre a revistas, jornais, livros e informações de segunda mão para construir seu trabalho.

Paulo Emílio dedica vários artigos à avaliação do livro de Alex Viany e à apreciação do estágio e qualidade dos estudos históricos no Brasil. A novidade do assunto entre o público, ou mais precisamente, entre um público que, teoricamente, seria mais informado já que leitor do suplemento, aparece expressa em uma de suas colunas:

Convém lembrar, ainda por menos agradável que se considere a asserção, que o cinema brasileiro nos exprime e revela. Aqui fica este parágrafo de introdução à guisa de resposta aos amáveis leitores desta coluna, que se surpreenderam com o interesse aqui demonstrado pela história do cinema brasileiro, a propósito do livro de Alex Viany, recentemente editado pelo Instituto Nacional do Livro. ${ }^{14}$

Deve-se perguntar a que estaria relacionado esse estranhamento do leitor: à dificuldade de situar o cinema brasileiro na história mundial do cinema? Afinal, era com esta categoria que se trabalhava até então: o cinema numa perspectiva mundial, que se desenrolara num tempo linear e sucessivo. Ou seria pelo fato de não se ver como espelho do cinema estrangeiro? O cinema no Brasil falhara na reprodução dos parâmetros estrangeiros. Se não era 'espelho', também não era 'o outro'. A filmografia não se afirmara como única e singular, retrato dos brasileiros.

Ao mesmo tempo, é preciso reconhecer a novidade do tema. Pouco se conhecia sobre a produção realizada no passado, e imperava a idéia de um cinema por se fazer. Essa idéia, aliás, esteve presente em diferentes momentos ao longo desses cem anos de produção cinematográfica. Foram vários os nascimentos e renascimentos do cinema nacional.

E, por fim, se não havia um cinema de qualidade no país, por que dedicar-lhe um livro de história? O cinema não se afirmara como um elemento dinâmico e fundamental na cultura nacional, portanto, não se reconhecia sua legitimidade para ser objeto da história. 
Se a história era uma preocupação constante naqueles tempos, o mesmo se pode dizer sobre o ofício do crítico.

Nas colunas de cinema de jornais, revistas e suplementos, uma questão era recorrente: a discussão sobre a crítica cinematográfica. Afirmam-se inúmeras vezes sua importância, critica-se sua fragilidade, denuncia-se sua má qualidade, divulgam-se novos parâmetros de referência. No entanto, um dos grandes problemas da crítica é a viabilização de canais que garantam seu exercício. A dificuldade de manutenção das revistas especializadas em crítica e teoria cinematográfica é um desses indícios, assim como o reduzido espaço ocupado pela crítica nas edições diárias dos jornais e seu constante anonimato, bem distante do destaque e importância dados à crítica literária. Ou talvez fosse o próprio cinema que ainda tentasse se desvencilhar dos rótulos de 'arte-indústria' ou 'arte-espetáculo', sempre o segundo termo fazendo sombra ao primeiro. Ou talvez ainda, o fracasso que rondava o cinema nacional, renegando-o a uma posição secundária se comparado a outras artes cuja expressão nacional já adquirira alguma vitalidade.

Entre aqueles que assinaram a coluna de cinema do Suplemento Dominical do Jornal do Brasil, dois assuntos foram recorrentes: o enfoque sobre o cinema brasileiro e a questão do exercício da crítica. As produções em andamento recebiam cobertura jornalística, e as em lançamento eram apreciadas criticamente. Dessa forma, jovens realizadores tinham seus trabalhos divulgados. Em meio à propaganda do cinema brasileiro, havia discussões e debates sobre os problemas da produção nacional.

Os problemas da crítica de cinema ocuparam o suplemento, principalmente nos seus primeiros anos. José Lino Grünewald, em artigo de janeiro de 1958 a respeito da publicação mineira, Revista de Cinema, sintetiza as questões mais problemáticas da crítica à época:

Empregando recursos e material mais modestos, de acordo com as possibilidades, a Revista de Cinema, com quatro anos de existência, vem conseguindo se manter e, pouco a pouco, melhorando. Nos moldes, é a única revista dotada de seriedade para tratamento do assunto que possuímos ... A função do crítico jamais deixou de ter importância em todas as fases de evolução nos diversos terrenos artísticos. A sua atuação incide em vários aspectos e no cinema, arte de imensa divulgação popular, o sentido educativo do seu papel avulta, principalmente aqui no Brasil, onde o índice cultural é relativamente baixo ... A compenetração dos fatores construtivos em seu mister marca a orientação do crítico autêntico. Analisar a obra através dos dados e elementos claros e objetivos, sob o 
ponto de vista da forma, esta a função radial: e também os válidos e/ou necessários paralelos no campo da sociologia, antropologia etc. ${ }^{15}$

Anos depois, no mesmo suplemento, Miguel Borges e Cláudio Bueno Cunha afirmam que a crítica cinematográfica das décadas de atividade "não conseguiu criar uma base disciplinar para o exame dos problemas ligados ao filme. Não há sequer uma linguagem comum às várias correntes críticas". ${ }^{16}$ Outros tinham posição mais positiva frente à crítica praticada no país. No entanto, não se furtavam a levantar a problemática, ressaltando, mesmo numa visão positiva, os problemas dessa atividade. E quando não avaliavam a atividade no Brasil, expunham acerca da necessidade da criação de balizas para o julgamento crítico.

O primeiro texto publicado por Francisco Luiz de Almeida Salles, crítico oficial de O Estado de S. Paulo desde 1951, no suplemento do jornal, intitulava-se "Didática da crítica de cinema". ${ }^{17} \mathrm{O}$ artigo, publicado no segundo mês do suplemento, expunha que, ao reconhecer o cinema como obra de criação artística, tornava-se fundamental definir padrões para a apreciação crítica que tivessem origem na própria produção e não em preferências culturais arbitrárias. O cinema, como toda obra de arte, não teria uma essência, mas sim um patrimônio a ser observado no ato da criação. Esse patrimônio seriam os usos dos meios materiais de sua criação ao longo dos anos de sua existência. Ao usar a expressão "referências culturais arbitrárias", o texto nos informa sobre o padrão de crítica vigente até então. Corrobora, ainda, de certa maneira, o artigo dos colegas do Rio de Janeiro que, ao denunciarem a falta de uma linguagem comum aos críticos, queriam dizer que faltavam padrões compartilhados.

A inconsistência da crítica seria mais um indício da pobreza da cultura cinematográfica local; afinal, o crítico era componente ativo dos processos culturais.

Ele deveria simultaneamente 'informar' e 'orientar', devendo ser capaz de sintetizar para seus leitores o pensamento dos realizadores. Somente um público informado pode selecionar o que o mercado deve oferecer. Não podemos nos esquecer que o público fora durante anos responsabilizado pelo sucesso das chanchadas em nossas telas.

Mas o crítico também é fundamental como elemento do processo criativo: "Ninguém contesta que a própria evolução da estética cinematográfica se deu, entre outros fatores, também através da contínua pregação feita pelos teóricos e críticos do cotidiano...." ${ }^{18}$ 
No Brasil, naquele momento, a ação pedagógica e a formação teórica eram colocadas como prerrogativas essenciais para o crítico.

\section{O CINEMA POR ENTRE PÁGINAS DE REVISTAS}

As revistas especializadas em cinema publicadas no Brasil tinham características diversas entre si. Havia publicações que pertenciam a grupos editoriais fortes, com circulação nacional, que serviam de veículo para o star system hollywoodiano e cujas principais fontes de renda estavam ligadas à publicidade de filmes norte-americanos anunciados por empresas distribuidoras ou por circuitos de exibição, caso de A cena muda, que circulou entre 1922 e 1955. A tônica dessas revistas era a vida de astros e estrelas, os bastidores de filmagens e notícias sobre os futuros lançamentos nas salas de cinema. Dessa maneira, compunham-se de farto material fotográfico com as fotos posadas dos artistas e com o still de filmagem. As críticas dos filmes eram constituídas de breves comentários sobre o enredo, o desempenho dos atores, o trabalho dos diretores, a fotografia, os diálogos, os cenários etc.

O espaço ocupado regularmente, ou seja, em seções fixas, pelo cinema nacional limitava-se a uma ou duas páginas, nas quais se buscava reproduzir o panteão das estrelas americanas com os atores e atrizes brasileiras - onde moravam, suas dicas de beleza, seus hábitos, seu cotidiano em família - e informar sobre as produções locais - enredo, direção, atores, locações. Em caso de haver a coluna de crítica cinematográfica, o que era comum, os filmes nacionais eram avaliados em sua maioria. Os problemas enfrentados pelo cinema brasileiro eram alvo constante de matérias nessas revistas, que defendiam a necessidade de uma produção local e a criação de mecanismos para incentivá-lo e protegê-lo da concorrência estrangeira. A revista Cinaerte, publicada entre 1926 e 1942, ficou conhecida pela divulgação e defesa do cinema brasileiro. Podemos localizar em jornais e revistas artigos que apontavam o baixo nível das produções nacionais e também duras críticas e esses mesmos periódicos.

É francamente incompreensível a atitude adotada por certo grupo de críticos do Rio de Janeiro, que vêm fazendo uma oposição sistemática e destrutiva do cinema nacional. Esses críticos têm se referido da forma a menos recomendável possível, quando comentam as películas nacionais ... Discordamos inteiramente daqueles pessimistas que procuram destruir a nossa nascente indústria cinema- 
tográfica ... Por que é que esses críticos letrados em estética de cinema (nós também somos um pouco) em história do cinema, em problemas econômicos de cinema, etc., etc., não aproveitam suas colunas para apontar o caminho que deve trilhar o cinema nacional? ${ }^{19}$

Dentro do atual panorama de um cinema brasileiro forçadamente inativo por falta de apoio do Governo e dos homens de capital, vale a pena estampar duas das cenas culminantes de O Cangaceiro, o filme de Lima Barreto que, gostem ou não os eternos inimigos do cinema brasileiro, é o maior espetáculo já filmado em nossa terra e que serviu para projetá-la nos festivais internacionais de cinema. Quis o destino, sempre caprichoso, que a vitória de O Cangaceiro fosse também um princípio de "debacle" de cinema brasileiro, com o fechamento dos estúdios Multifilmes, o desencanto natural de Alberto Cavalcanti, a queda vertiginosa e irremediável da Cia. Vera Cruz e a morte de Moacir Fenelon, um pioneiro de nossos filmes e acima de tudo um idealista sincero. Pode parecer que a ordem de fatos aqui arrolados esteja em desacordo com a ordem cronológica. Pouco importa! Certo é que O Cangaceiro continua sendo a única demonstração de arte do cinema nacional. ${ }^{20}$

Nos dois artigos é clara a idéia de um cinema nacional em construção, expressa na avaliação do filme $O$ Cangaceiro, no comentário sobre a derrocada dos estúdios paulistas, na referência a determinadas figuras que atuaram no campo cinematográfico e, principalmente, no questionamento sobre a atuação da imprensa. Que papel deve desempenhar a crítica no processo de formação desse cinema? A idéia de que havia um cinema por se fazer no país - processo que já estaria em curso - sobrevalorizava qualquer texto que a ele se referisse. $\mathrm{O}$ cinema se fazia pelos filmes, mas também pelas palavras, na medida em que a imprensa poderia discutir seus problemas, avaliar sua evolução, encampar propostas, divulgar realizações e desempenhar um importante papel de mediador entre público e realizadores. A imprensa colocava-se como componente ativa na construção da indústria cinematográfica no país.

O espaço ocupado pelos artigos sobre técnica e linguagem cinematográfi$\mathrm{cas}^{21}$ e pelos que enfocavam os problemas enfrentados pelo cinema brasileiro era reduzido se comparado às demais seções. A tônica recaía sobre a divulgação dos filmes e a atuação de pessoas ligadas ao cinema, como diretores, fotógrafos e atores. No caso de Jornal do Cinema, por exemplo, revista sob direção de Alex Viany, publicada entre 1951 e 1957, as críticas e as matérias mais apro- 
fundadas sobre cinema, como os problemas da Vera Cruz, abordados em artigo de Ely Azeredo publicado no número 34, e o neo-realismo, eram exceções.

Percebe-se, de maneira geral, ênfases diferenciadas nos assuntos abordados pela crítica de cinema produzida no jornal e nessas revistas, apesar do grande trânsito de jornalistas por esses dois canais. O próprio formato das publicações explica, em parte, essas diferenças. O jornal oscilava entre a referência herdada das primeiras revistas de cinema e o padrão da crítica literária presente na imprensa diária. Os primeiros periódicos dedicados ao cinema surgiram por volta da década de 1920 e neles difundia-se a idéia do cinema como diversão e arte. As revistas especializadas posteriores deram continuidade a esse padrão estabelecido nos primeiros periódicos: farto material fotográfico, grande enfoque na vida pessoal dos artistas, divulgação das técnicas cinematográficas, comentários sobre as filmagens em curso. Os jornais, por sua vez, eram pobres em imagens e faziam maiores investimentos nos textos, concentrando-se mais nos filmes sem, no entanto, deixar de lado o enfoque sobre os artistas.

As revistas de cunho ensaístico, por sua vez, depararam-se freqüentemente com problemas editoriais e financeiros e com a dificuldade de garantir a regularidade das publicações. Muitas não passaram de alguns poucos números, caso de O Fan (1928), a primeira tentativa no gênero, com nove números, e Filme (1949), com apenas dois números. Somente na década de 1950 esse gênero de periódico conseguiu se estabelecer, com as publicações mineiras Revista de Cinema (1954-1957, 1961-1964) e Revista de Cultura Cinematográfica (19571963) que, apesar de algumas dificuldades e da distribuição precária, eram vendidas nas principais cidades do país. Revista de Cinema foi considerada por muitos, à época, um padrão de crítica, sendo freqüentes as referências à revista $\mathrm{e}$ aos seus jornalistas na imprensa de São Paulo e do Rio de Janeiro. ${ }^{22}$ Mais do que isso, fora saudada como um passo a mais na construção da cultura cinematográfica brasileira e, conseqüentemente, do cinema nacional.

Diversas revistas não especializadas no assunto dedicavam espaço ao cinema, caso de O Cruzeiro, que durante muitos anos teve Alex Viany como responsável pela coluna. Embora essas revistas não constituam aqui alvo de análise, elas nos servem para indicar que havia um trânsito dos jornalistas em diferentes veículos, como colaboradores fixos ou eventuais, ou ainda, por cessão de artigos, o que significava a publicação repetida de um mesmo texto.

Nas revistas de proposição teórica e nos suplementos dos jornais, os ensaios eram espaços nos quais se buscava organizar parâmetros para a crítica, pois a reflexão sobre o cinema poderia ter e geralmente alcançava uma forma 
mais elaborada, seguindo o perfil proposto para os cadernos culturais. Nesses textos, encontram-se indícios dos conflitos existentes em torno do crítico e do seu trabalho e das diferentes propostas - éticas, estéticas, econômicas e políticas - para o cinema em circulação naquele momento.

A crítica tornou-se, ao longo da década de 1950, um importante interlocutor com uma geração de cineastas e de freqüentadores dos cineclubes que proliferaram pelo país a partir dos anos 30 . Muitos futuros cineastas e membros de cineclubes exerceram a função de críticos, como foi o caso de Maurice Capovilla, Glauber Rocha, Walter Lima Júnior e Geraldo Sarno, e entre si — parte dos críticos, dos realizadores e dos cineclubistas - compartilhavam uma mesma aspiração cinematográfica, que se traduzia em críticas e ensaios, na propagação de estudos de importantes teóricos estrangeiros e na divulgação de inúmeros filmes.

\section{CONSIDERAÇÕES FINAIS}

As mudanças na linha editorial do $J B$, percebidas no conjunto das publicações da época, demonstra as alterações do estatuto do cinema no país. Os modos de veiculação, percepção e compreensão em torno do cinema dizem respeito à constituição de uma determinada situação de consumo cultural, ${ }^{23}$ o que significa reconhecer a existência de uma situação de produção e de recepção que varia no tempo, no espaço e entre as diferentes comunidades de espectadores.

Desde o início dos anos 50, duas questões eram fundamentais para os realizadores e para a crítica em geral: a viabilização de novas formas de produção frente às dificuldades de sobrevivência dos estúdios no país e a defesa do estatuto do cinema como arte e forma de expressão cultural de um país. Em torno desses pontos foram organizados os primeiros congressos de cinema, primeiro em âmbito estadual, em São Paulo, e em seguida nacional. O contato com algumas das cinematografias estrangeiras levantava questões, tais como o investimento em gêneros como o documentário e a realização de fitas a baixos custos. A defesa do estatuto do cinema como arte e expressão cultural, naquele momento, buscava dotar a produção cinematográfica de um novo significado:

Portanto, entre as condições que devem ser preenchidas para que um produto intelectual seja produzido, está a produção da crença no valor do produto. Se querendo produzir um objeto cultural, qualquer que seja, eu não produzo si- 
multaneamente o universo de crença que faz com que seja reconhecido como um objeto cultural, como um quadro, como uma natureza morta, se não produzo isto, não produzi nada, apenas uma coisa. (Chartier, 1996, p.239-240)

O cinema seria, portanto, uma arte na qual cabia distinguir o que lhe dava valor específico. Com base nessa definição seria possível avaliar os filmes e distingui-los entre si. Esse valor específico é igualmente um valor normativo, na medida em que visa justificar a existência do cinema no espaço social total. Dessa forma, surge tanto um sistema de normas que regram a maneira como se deve apreender o cinema quanto códigos que regram a inteligibilidade do discurso cinematográfico. ${ }^{24} \mathrm{~A}$ hierarquização e a distinção criam categorias de filmes e, logo, diferentes comunidades de espectadores.

Juntamente com a consolidação de uma cultura cinematográfica na imprensa escrita, de caráter teórico e ensaístico na forma dos suplementos e de revistas, teve início a reflexão sobre a tradição nessa área. Ao lado da crítica aos poderes públicos e ao empresariado sobre os descaminhos de cinematografia verde e amarela, emergia a discussão que se esboçava no artigo de José Lino Grünewald e José Carlos de Oliveira no Jornal do Brasil: a pobreza da cultura cinematográfica da sociedade brasileira embotava a avaliação dos filmes e se tornava patente até mesmo nos filmes produzidos.

A divulgação de novos referenciais por parte da imprensa e dos próprios filmes representou mudanças na recepção dos espectadores e em seu horizonte de expectativas, o que, conseqüentemente, implicou modificações entre os que produziam. Se a consumação cultural é ao mesmo tempo criação e produção ativa de outra coisa, ${ }^{25}$ a produção ocorre dentro de um campo de possibilidades identificado por quem o faz. As partes - realizadores, espectadores, exibidores, produtores - não se encontram em campos distintos, e sim, no mesmo, num jogo constante de forças; a mudança em um elemento altera a composição de forças e expectativas envolvidas. ${ }^{26}$

Falar em imprensa nos anos 50 compreende um vasto número de publicações dos mais diferentes enfoques, estilos e preocupações. Mas podemos identificar a configuração de um tipo específico de produção no campo editorial que constitui indício e agente da modificação do estatuto do cinema no país.

\section{NOTAS}

${ }^{1}$ ABREU, Alzira Alves de (Org). A imprensa em transição. Rio de Janeiro: Ed. FGV, 1996.

${ }^{2}$ Jornal do Brasil, Rio de Janeiro, 10 jun. 1966, Caderno B, p.9. 
${ }^{3}$ O Estado de S. Paulo, 9 set. 1956, $1^{\circ}$ caderno, p.12.

${ }^{4}$ Francisco Luiz de Almeida Salles, o crítico oficial do jornal O Estado de S. Paulo desde 1950, somente passou a assinar as colunas diárias quando outros colegas iniciaram a atividade crítica cinematográfica.

${ }^{5}$ A Cinemateca Brasileira foi constituída como sociedade civil em 1956 e veio a substituir a Filmoteca do MAM criada na década de 1940. SOUZA, José Inácio de Melo. Paulo Emílio no paraíso. Rio de Janeiro: Record, 2002.

${ }^{6}$ GOMES, Paulo Emílio Salles. O Congresso de Dubrovnik. O Estado de S. Paulo, 13 out. 1956, Suplemento Literário, p.5.

${ }^{7}$ GOMES, Paulo Emílio Salles. A volta aos filmes. O Estado de S. Paulo, 13 set. 1958, Suplemento Literário, p.5.

8 "Uma cinemateca assemelha-se a um Museu de Belas Artes e a um Arquivo Histórico, sendo que num estágio superior de desenvolvimento, ao facultar de forma extensa a leitura individual dos filmes de seu acervo, apresenta certo aspecto de Biblioteca Nacional." GOMES, Paulo Emílio Salles. Cultura e custo. O Estado de S. Paulo, 30 ago. 1958, Suplemento Literário, p.5.

${ }^{9}$ Em 1955 Moniz Viana e Ruy Pereira da Silva criaram o Departamento de Cinema do futuro Museu de Arte Moderna do Rio de Janeiro, dedicado à divulgação de antigos clássicos, exibidos no auditório da Associação Brasileira de Imprensa. Dois anos mais tarde, transformou-se em Cinemateca do MAM. Somente em 1959, quando o crítico José Sanz assumiu a direção, teve início sua ação propriamente dita como cinemateca.

10 "A Retrospectiva Internacional, de março a dezembro de 1954, constituiu a maior oportunidade de formação cultural cinematográfica jamais apresentada na América Latina. É possível que esta iniciativa não tenha tido o aproveitamento desejado, que suas proporções tenham sido prematuras. Mas continuo a pensar que durante aqueles dez meses os quadros limitados de cultura cinematográfica existentes em São Paulo viveram experiências decisivas e que se iniciaram então o aprofundamento e a extensão do interesse e dos estudos posteriores que continuam ainda e que acabarão dando os frutos esperados." GOMES, Paulo Emílio Salles. O cinema na Bienal. O Estado de S. Paulo, 6 jun. 1957, Suplemento Literário, p.5.

${ }^{11}$ GOMES, Paulo Emílio Salles. Cursos de cinema. O Estado de S. Paulo, 21 dez. 1957, Suplemento Literário, p.5.

${ }^{12} \mathrm{O}$ livro foi publicado pelo Instituto Nacional do Livro em 1959 e relançado posteriormente em 1987 numa co-edição Alhambra-Embrafilme sem a filmografia que constava originalmente.

${ }^{13}$ A publicação até o número 33 compunha-se de matérias sobre artistas e a produção de filmes, palavras cruzadas, notas sobre a sociedade e letras de música, sendo Alex Viany seu diretor-geral. A partir do número 34 houve mudança de equipe e o periódico passou a se 
dedicar mais especificamente ao cinema. Algumas colunas e matérias passaram a ser assinadas e a crítica se amplia, assim como as matérias sobre assuntos gerais sobre cinema. A partir da reforma, o cinema estrangeiro passou a ter mais espaço na revista. Fizeram parte do Jornal de Cinema Moniz Vianna, Ely Azeredo, Pedro Lima, José Sanz e Alberto Shatovsky; e, entre os colaboradores, Salvyano Cavalcanti de Paiva, Walter da Silveira, Carlos Ortiz e Pery Ribas.

${ }^{14}$ GOMES, Paulo Emílio Salles. Decepção e esperança. O Estado de S. Paulo, 6 fev. 1960, Suplemento Literário, p.5.

${ }^{15}$ GRÜNEWALD, José Lino. Jornal do Brasil, Rio de Janeiro, 19 jan. 1958, Suplemento Dominical, p.4.

${ }^{16}$ BORGES, Miguel Borges; BUENO, Cláudio. Jornal do Brasil, Rio de Janeiro, 17 out. 1959. Suplemento Dominical, p.7.

${ }^{17}$ SALLES, Francisco Luiz de Almeida. O Estado de S. Paulo, 10 nov. 1956, Suplemento Literário, p.5.

${ }^{18}$ SIQUEIRA, Cyro. A revisão do método crítico. Revista de cinema, Belo Horizonte, n.1, abr. 1954, p.5.

${ }^{19}$ Jornal do cinema, Rio de Janeiro, n.20, jan. 1953, p.17.

${ }^{20}$ A cena muda, Rio de Janeiro, n.30, 7 set. 1954, p.20.

${ }^{21}$ Nas primeiras revistas publicadas no país esses assuntos eram abordados mais freqüentemente, pois julgava-se necessário ensinar pela escrita a gramática da linguagem cinematográfica.

22 "Nos moldes, é a única revista dotada de seriedade para tratamento do assunto que possuímos. É, na realidade, bom o conteúdo das páginas e, pelo menos, torna-se fácil constatarmos que se o cinema brasileiro continua passando mal, uma parte de nossa crítica vai bem, no entanto." GRÜNEWALD, José Lino, Revista de Cinema. Jornal do Brasil, Rio de Janeiro, 19 jan. 1958, Suplemento Dominical, p.4. "De vez em quando, surgem no Rio ou em São Paulo projetos para a criação de uma revista cinematográfica de nível alto. Na minha opinião, o que as pessoas interessadas podem fazer de melhor atualmente é canalizar seus esforços na ajuda ao que está sendo feito em Belo Horizonte. Chegou o momento de cuidarmos dos problemas da cultura cinematográfica em termos nacionais. Se for possível dar à Revista de Cinema a estabilidade de que necessita e o prestígio que merece, isso significará o início de uma etapa superior em nossa vida cultural cinematográfica." GOMES, Paulo Emílio Sales. Primazia mineira. O Estado de S. Paulo, 31 ago. 1957, Suplemento Literário, p.5.

${ }^{23}$ A LEITURA: uma prática cultural — debate entre Pierre Bourdieu e Roger Chartier. In: CHARTIER, Roger (Org.). Práticas de leitura. Trad. Cristiane Nascimento. 2.ed. São Paulo: Estação Liberdade, 1996. p.231-253.

${ }^{24}$ SIMIARD, Denis. De la nouveauté du cinéma des premiers temps. In: GAUDREAULT, 
André; LACASSE, Germain; REYNAUD, Isabelle (Org.). Le cinéma en histoire - institution cinématographique, réception filmique et reconstitutions historique. Quebec: Ed. Nota Bene, 1999. p.29-56.

${ }^{25}$ CERTEAU, Michel. A invenção do cotidiano - 1. Artes de fazer. Trad. Ephraim Ferreira Alves. Petrópolis (RJ): Vozes, 1994.

${ }^{26}$ BOURDIEU, Pierre. O poder simbólico. Trad. Fernando Tomaz. Rio de Janeiro: Bertrand Brasil, 1989.

Artigo recebido em fevereiro de 2008. Aprovado em abril de 2008. 